\title{
The Driving Forces Analysis of Economic Growth in Henan Province
}

\author{
Zhang Kaiguang $^{1, a^{*}}$, Ba Mingting ${ }^{1, b}$, Sun Yanmin ${ }^{1, \mathrm{c}}$, Meng Hongling ${ }^{1,2, \mathrm{~d}}$ \\ ${ }^{1}$ Institute of 3S Technology, Zhengzhou Normal University, Zhengzhou, China \\ ${ }^{2}$ Institute of Curriculum and Instruction, East China Normal University, Shanghai China

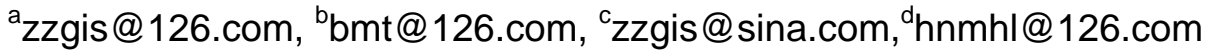

Keywords: Henan province; classification; loading coefficient; growth rate; driving force

\begin{abstract}
The method of statistical analysis is used to analyze the data of the classification value-added growth in Henan province from 1998 to 2012. The 11 industries loading coefficients for the provincial economic growth are designed to study the change rules of the economic growth, the temporal relationship of classification value-added growth and overall economic growth, the main driving forces, as well as the potential driving forces in the future. The results show that the main driving forces of economic growth successively come from animal husbandry, forestry, information transmission \& software \& information technology services and construction industry in the year of 2012, and the potential driving forces successively come from transportation \& storage \& postal industry, services of farming \& forestry \& animal husbandry \& fishery, wholesale \& retail trades \& hotels \& catering industry and farming in future.
\end{abstract}

\section{Introduction}

Henan Province, located in the heart of mainland of China, is the main body of Central Plains Economic Region, an important support location to the economic development of the eastern coastal region, a strategy engine of economic development for the western China as well. It plays an important role in linking the east to the west under china national western development strategy [1, 2].

Central Plains Economic Region is clearly identified as a special economic region of the 'National Main Function Planning' in June of 2011 following three major economic Regions as 'Bohai Rim', 'Yangtze River Delta' and 'Zhujiang River Delta region', which is composed of Henan province and other 10 cities coming from 6 surrounding provinces named as Shandong, Jiangsu, Hebei, Shanxi, Anhui, Hubei, etc.. It plays an vital strategic role in the situation of china national reform and development due to its important geographical location, developed regional transportations, tremendous potential markets and profound culture foundations[3,4].

By 2012, the economic growth rates of Henan province have been continuously higher than that of the national average for 19 years, GDP have reached 2.96 trillion yuan, and kept double-digit economic growths for consecutive 10 years, accounting for $5.7 \%$ of the national total economic output which ranked No.5 in the nation, and reaching 31,500 yuan per capita GDP. However, for the most populous province in China, it has a large gap located in its economic structure, quality, efficiency and other indicators with the national averages, such as the public revenue, the disposable income of urban residents and rural residents to the national total shares respectively are 3.3\%, 83.2\% and $95.0 \%$ and ranked No. 5, 20 and 16 [5]. The only way to achieve sustainable rapid economic development and fully play the strategic advantages in Central Plains Economic Region is to optimize the economic structure, seek for more economic growth points with optimal structure, high quality, good performance and enough stamina based on traditional advantages of economic development[6,7].

The paper uses statistical analysis to study the development rules of the classification value-added growth rates in main industries of national economy in Henan province from 1998 to 2012, to obtain 
the temporal relationship of classification value-added growth and overall economic growth. It is beneficial to understand the main driving forces of economic growth, deeply study the weaknesses of rapid economic growth, and search the potential driving forces to fully ensure the sustainable and rapid development of Central Plains Economic Region.

\section{Data and Processing}

Data. On the basis of comprehensive, comparable, representative and operational principles, along with the reference of the industrial classification standard of national economy[8], the indicators in this study include 11 industries[9], which are agriculture (farming, forestry, animal husbandry(A H), fishery, services for farming \& forestry \& animal husbandry \& fishery(F\&F\&A\&F)), industry (light(L-industry), heavy(H-industry)), construction((C-industry)), transportation \& storage \& postal industry(T\&S\&P), information transmission \& software \& information technology services(I\&T\&S), wholesale \& retail trades $\&$ hotels \& catering industry $(\mathrm{W} \& \mathrm{R} \& H \& \mathrm{C})$. The agriculture and industry in this analysis are refined for Henan is a major agricultural province and heavy industry production base of the country. The value-added of each classification for continuous two year are used to calculate the classification value-added economic growth rate. All data come from Henan Statistical Yearbook (1998 to 2013), which are integrity, reliability and authority.

Data Processing. For the existence of comparable price problem between different years, all data are transformed to the constant price of 2010. The calculation method is as the following,

$$
p_{i, j}=\alpha_{i} q_{i, j} \quad(i=1998, \cdots 2012 ; j=1,2 \cdots 11)
$$

where $\alpha_{i}$ is the conversion coefficient conducted from the constant prices of 2010 for $i$ is year and $j$ classification, $p_{i, j}$ is transformed data, $q_{i, j}$ is raw data from Henan Statistical Yearbook ( 1998 to 2013).

Because of the existence of significant different measures between different classifications, it is necessary to standardize the constant price, calculated as follows,

$$
m_{i, j}=\frac{q_{i, j}-\overline{q_{j}}}{\sigma_{j}} \quad(i=1998, \cdots 2012 ; j=1,2 \cdots 11)
$$

where $m$ is standardized classification values of year $i$ and classification $j \cdot \overline{q_{j}}$ and $\sigma_{j}$ respectively are the standard deviation and the mean of classification $j$.

After completing of the data processing, the relative annual growth rate $\delta_{i, j}$ is calculated using the following formula, and the calculation results are listed in Table 1.

$$
\delta_{i, j}=\frac{m_{i, j}-m_{i, j-1}}{m_{i, j-1}}(i=1998, \cdots 2012 ; j=1,2 \cdots 11)
$$

Research Methods. The research uses the principal component analysis method, by year recursion and data iteration to calculate classification component matrix, and construct classification value-added growth coefficient, to complete the analysis.

Principal component analysis is one of the main methods of data mining. It simplifies a dependent variables set with a few independent factors, which are the linear combinations of the original variables group, the coefficients of the linear combination stand for the variable correlation. The data analysis is conducted by the part of simplified factors. Its advantage is to eliminate the influence on analysis results deriving from the overlapping information between the original variables, and to complete the date analysis with the least factors based on maintaining the original data information as much as possible. 
Suppose $X$ stands for the sample set with $n$ samples and $m$ variables. The main analysis steps are as the following:

Step 1. The sample data transformation

The main purpose of the data transformation of the sample is to eliminate the influence on the analysis results coming from the different numerical area and different dimension of original variables, makes all variables be in the same standard comparison. The commonly methods of the sample data transformation have centralized transformation, standardized transformation, range standardized transformation, range normalized of transformation and logarithmic transformation, etc. The method of data standardization transformation is used as Eq.2.

Table 1.The Classification Value-added Relative Growth Rates 1998 to 2012) in Henan Province

\begin{tabular}{|c|c|c|c|c|c|c|c|c|c|c|c|}
\hline year & $\begin{array}{c}\text { Farm- } \\
\text { ing }\end{array}$ & $\begin{array}{c}\text { Forest } \\
\text {-ry }\end{array}$ & A H & $\begin{array}{c}\text { Fish- } \\
\text { ery }\end{array}$ & $\begin{array}{l}\text { F\&F } \\
\text { FA\& }\end{array}$ & $\begin{array}{c}\text { L-ind } \\
\text { ustry }\end{array}$ & $\begin{array}{c}\text { H-ind } \\
\text { ustry }\end{array}$ & $\begin{array}{c}\text { C-ind } \\
\text { ustry }\end{array}$ & $\begin{array}{c}\text { T\&S } \\
\& P\end{array}$ & $\begin{array}{c}\text { I\&T\& } \\
\text { S }\end{array}$ & $\begin{array}{c}\text { W\&R } \\
\text { \&H\& } \\
\text { C }\end{array}$ \\
\hline 1998 & 5.40 & 4.70 & 9.70 & 14.60 & 7.00 & 4.10 & 9.20 & 0.98 & 5.15 & 61.02 & 9.70 \\
\hline 1999 & 8.20 & 3.00 & 6.20 & 6.30 & 7.20 & 7.00 & 7.80 & 16.67 & 3.71 & 33.66 & 8.00 \\
\hline 2000 & 3.20 & 5.20 & 6.60 & 10.20 & 4.50 & 6.20 & 14.20 & 12.24 & 5.33 & 35.05 & 10.56 \\
\hline 2001 & 5.40 & -3.60 & 7.10 & 0.20 & 5.50 & 9.30 & 10.10 & 36.43 & 4.81 & 33.80 & 10.81 \\
\hline 2002 & 3.80 & 3.20 & 5.40 & 15.30 & 4.50 & 10.80 & 15.70 & 20.73 & 5.65 & 26.53 & 10.66 \\
\hline 2003 & -9.90 & 8.00 & 6.90 & 8.30 & 6.90 & 15.20 & 21.90 & 21.67 & -3.45 & 37.86 & 10.75 \\
\hline 2004 & 18.80 & 5.50 & 6.80 & 9.90 & 5.00 & 19.80 & 25.40 & 56.92 & 9.64 & 43.60 & 15.71 \\
\hline 2005 & 7.70 & 4.70 & 7.60 & 19.00 & 4.00 & 28.80 & 21.00 & 33.96 & 7.95 & 27.66 & 15.06 \\
\hline 2006 & 7.70 & 7.40 & 6.60 & 18.60 & 2.30 & 24.60 & 22.80 & 40.47 & 10.76 & 29.64 & 16.32 \\
\hline 2007 & 4.70 & 5.00 & 1.50 & 11.70 & 4.10 & 25.00 & 23.90 & 49.90 & 15.89 & 29.34 & 19.27 \\
\hline 2008 & 4.70 & 7.50 & 6.70 & 8.50 & 4.70 & 24.80 & 17.60 & 45.47 & 14.77 & 20.46 & 23.99 \\
\hline 2009 & 2.90 & 7.20 & 5.80 & 6.30 & 5.20 & 13.70 & 15.00 & 29.29 & 16.84 & 15.37 & 16.01 \\
\hline 2010 & 4.20 & 4.30 & 4.90 & 7.40 & 4.80 & 20.00 & 18.80 & 30.76 & 17.72 & 16.19 & 18.64 \\
\hline 2011 & 4.20 & 7.00 & 2.00 & 6.90 & 5.30 & 20.40 & 19.20 & 19.01 & 17.55 & 19.59 & 18.11 \\
\hline 2012 & 4.20 & 4.90 & 4.60 & 5.70 & 5.90 & 16.20 & 13.90 & 15.11 & 10.63 & 13.76 & 15.46 \\
\hline
\end{tabular}

Step 2. The extraction factors

It is necessary to determine the minimum value $t_{\min }$ containing the original data information before the statistical analysis. This study determines the minimum value as $90 \%$ to ensure that the analysis is convenient, and fully retain the maximum information of the original data.

Firstly, calculate the correlation coefficient matrix $R$ of the sample $X$, and remove the complete linearly dependent variables. Secondly, calculate the eigenvalues $\left(\lambda_{1} \geq \lambda_{2} \geq \cdots \quad \lambda_{m} \geq 0\right)$ of $\mathrm{R}$, and determine the values of the extraction factor $k=\min \left\{i \mid \sum_{t=1}^{i} \lambda_{t} / \sum_{t=1}^{m} \lambda_{t} \geq t_{\min }\right\}$.

Step 3. The loading coefficients

According to $k$, calculate all factor loading coefficients, judge the factor dependency to ensure all factor dependency within the scope of the permit, and then complete the necessary analysis.

Table 2. The Loading Coefficients of the Classification Value-added Growth Rates in 2008

\begin{tabular}{|c|c|c|c|c|c|c|c|c|c|c|c|}
\hline $\begin{array}{l}\text { Com } \\
\text { pone } \\
\text { nt }\end{array}$ & $\begin{array}{c}\text { Farm- } \\
\text { ing }\end{array}$ & $\begin{array}{c}\text { Forest } \\
\text {-ry }\end{array}$ & A H & $\begin{array}{c}\text { Fish- } \\
\text { ery }\end{array}$ & $\begin{array}{l}\text { F\&F\& } \\
\text { A\&F }\end{array}$ & $\begin{array}{c}\text { L-ind } \\
\text { ustry }\end{array}$ & $\begin{array}{c}\text { H-ind } \\
\text { ustry }\end{array}$ & $\begin{array}{c}\text { C-ind } \\
\text { ustry }\end{array}$ & $\begin{array}{c}\text { T\&S } \\
\& P\end{array}$ & $\begin{array}{c}\text { I\&T\& } \\
\text { S }\end{array}$ & $\begin{array}{c}\text { W\&R } \\
\text { \&H\& } \\
\text { C }\end{array}$ \\
\hline 1 & 0.31 & 0.42 & -0.54 & 0.39 & -0.80 & 0.92 & 0.80 & 0.84 & 0.81 & -0.61 & 0.88 \\
\hline 2 & -0.34 & 0.77 & 0.35 & 0.72 & -0.05 & 0.14 & 0.32 & -0.37 & -0.26 & 0.28 & -0.05 \\
\hline 3 & 0.84 & -0.14 & 0.46 & 0.30 & -0.12 & -0.06 & -0.11 & 0.05 & 0.30 & 0.49 & -0.02 \\
\hline 4 & 0.02 & 0.25 & 0.14 & -0.43 & 0.47 & 0.11 & 0.28 & 0.33 & -0.08 & 0.37 & 0.22 \\
\hline 5 & -0.13 & 0.11 & 0.43 & -0.10 & 0.05 & 0.07 & -0.36 & -0.11 & 0.19 & -0.24 & 0.37 \\
\hline Total & 0.70 & 1.41 & 0.84 & 0.88 & -0.45 & 1.18 & 0.93 & 0.74 & 0.96 & 0.30 & 1.41 \\
\hline
\end{tabular}




\section{The Classification Value-added Growth Rates Analysis in Henan Province}

The Loading Coefficients of the Classification Value-Added Growth Rates. The calculation of loading coefficients of the classification value-added growth rates in 2008 is based on the classification value-added growth rates in the Table 1 . First of all, the correlation coefficient matrix, eigenvalues and eigenvectors located in the first 11 line and 11 column matrix of Table 1 are calculated, and then the top five principal components which contain $90.39 \%$ of the original data information are extracted according to the standard of minimum extraction $t_{\min }=90 \%$. The principal component factor loading coefficients is shown in Table 2.

Define the loading coefficients of the classification value-added growth rates are the sum of loading coefficients of corresponding principal component factors, such as that of 2008 in the last line of Table 2. Here, the classification value-added growth data of 11 years from 1998 to 2008 are used to calculate the loading coefficients of the classification value-added growth rates in order to fully guarantee the invertibility of correlation coefficient matrix and the continuity of the calculation results, accordingly lead the conclusion could reflect the objective reality.

Table 3. The loading coefficients of the classification value-added growth rates (2008 2012)

\begin{tabular}{|l|r|r|r|r|r|r|r|r|r|r|r|}
\hline Year & $\begin{array}{c}\text { Farm- } \\
\text { ing }\end{array}$ & $\begin{array}{c}\text { Forest } \\
\text {-ry }\end{array}$ & A H & $\begin{array}{l}\text { Fish } \\
\text {-ery }\end{array}$ & $\begin{array}{l}\text { F\&F\& } \\
\text { A\&F }\end{array}$ & $\begin{array}{l}\text { L-ind } \\
\text { ustry }\end{array}$ & $\begin{array}{c}\text { H-ind } \\
\text { ustry }\end{array}$ & $\begin{array}{c}\text { C-ind } \\
\text { ustry }\end{array}$ & $\begin{array}{c}\text { T\&S } \\
\text { \&P }\end{array}$ & $\begin{array}{c}\text { I\&T\& } \\
\text { S }\end{array}$ & $\begin{array}{c}\text { W\&R } \\
\text { \&H\& } \\
\text { C }\end{array}$ \\
\hline 2008 & 0.70 & 1.41 & 0.84 & 0.88 & -0.45 & 1.18 & 0.93 & 0.74 & 0.96 & 0.30 & 1.41 \\
\hline 2009 & 0.73 & 0.68 & 0.52 & 0.18 & -0.13 & 1.31 & 1.57 & 1.61 & 0.08 & 1.03 & 0.98 \\
\hline 2010 & 1.22 & 0.43 & 0.72 & 0.11 & 0.01 & 1.24 & 1.33 & 1.74 & 0.07 & 0.96 & 0.87 \\
\hline 2011 & 0.03 & 1.55 & 0.66 & 0.75 & 0.02 & 1.33 & 1.68 & 0.93 & -0.38 & 0.82 & 0.75 \\
\hline
\end{tabular}

The loading coefficients of the classification value-added growth rates (2009 to 2012)(Table 3) are calculated from the classification value-added growth data over its first 11 years data (Table 1) by the truncating and iterating methods. The ratios of the information extraction with the first five principal components are respectively as 91.92\%, 92.93\%, 93.09\% and 92.71\%.

The Horizontal Analysis of the Classification Value-Added Growth Rates in Henan Province. Fig. 1 is the curves of the annual classification value-added growth rates in Henan province according to Table 3. It could be found that the value-added growth in 2008 mainly comes from the three industries as the forestry, wholesale \& retail trades \& hotels \& catering industry and light industry. The value-added growths of the three industries as construction, information transmission \& software \& information technology services, services of farming \& forestry \& animal husbandry \& fishery are below the average level. Overall the value-added growth of services of farming \& forestry \& animal husbandry \& fishery is the weakest part in the province in 2008, even there is a $4.7 \%$ annual growth.

The value-added growth in 2009 mainly comes from the four industries as construction, heavy industry, light industry and farming. The value-added growths in the five industries as forestry, animal husbandry, fishery, transportation \& storage \& postal industry and services of farming \& forestry \& animal husbandry \& fishery are below the average level. generally the value-added growth of services of farming \& forestry \& animal husbandry \& fishery is the weakest part in the province in 2009, even there is a $5.2 \%$ annual growth.

The value-added growth in 2010 mainly comes from the four industries as construction, heavy industry, light industry and farming. The value-added growths in five industries as forestry, animal husbandry, fishery, transportation \& storage \& postal industry, and services of farming

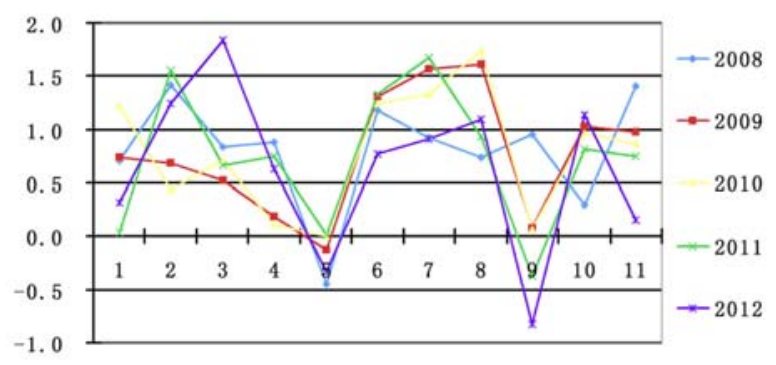

Fig.1. The Classification Value-added Growth Rates by Year \& forestry \& animal husbandry \& fishery are below the average level. 
The value-added growth in 2011 mainly comes from the three industries as heavy industry, light industry and forestry. The value-added growths in the four industries as animal husbandry, farming, transportation \& storage \& postal industry, and services of farming \& forestry \& animal husbandry \& fishery are below the average level.

The value-added growth in 2012 mainly derives from the three industries as animal husbandry, forestry, information transmission \& software \& information technology services. The value-added growths in the four industries as farming, wholesale \& retail trades \& hotels \& catering industry, services of farming \& forestry \& animal husbandry \& fishery, transportation \& storage \& postal industry are below the average level.

The Vertical Analysis of the Classification Value-Added Growth Rates in Henan Province. Fig. 2 is the curves of the classification value-added growth rates in Henan province according to Table 3, which shows that (1) The contribution ratios of farming value-added growth to the total economic growth of the province respectively rank as 9, 6, 4, 9 and 8 for the five-year, the contributions increase gradually from 2008 to 2010, but have an obvious decline in 2011, then a return to upswing in 2012. (2) The provincial economic growth mainly comes from the forestry in 2008, but the accounting ratios reduce by the first ranking to the eighth from the year of 2008 to 2010, there are a rapid growth in 2011 and a decline in 2012. (3) The provincial economic growth coming from the animal husbandry continuously keep lower level between 2008 and 2011, however the contribution ratio increases rapidly and become the main contributor of the economic growth throughout the year of 2012. (4) The situations of fishing and forestry are basically the same, but the contribution ratios of the fishing are lower than that of the forestry. (5) The services of farming \& forestry \& animal husbandry \& fishery has gone a parabolic tendency throughout the 5 years, and is the smallest industry contributor. (6) The basic

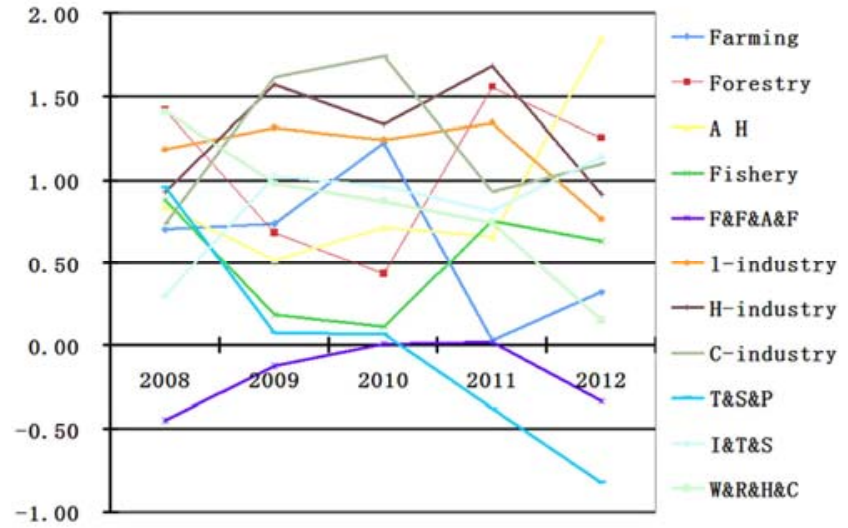

Fig.2. The Classification Value-added Growth Rate by Classification trend of light industry is stable from 2008 to 2011. The contribution ratios remain at the third level, however there is a small decline in 2012. (7) The provincial economic growths mainly come from the heavy industry between 2008 and 2011, however there is a significantly decrease in 2012 which drops from the first in 2011 to the fifth in 2012. (8) The developments of the construction industry are fast and become the main contributor of the provincial economic growths from 2009 to 2010, but there is an obvious decline in 2011 and a rebound in 2012. (9) The ratios of the industry contribution to the provincial economic growth as transportation \& storage \& postal industry gradually reduce from 2008 to 2012. (10) The ratios of the contribution to the provincial economic growth as information transmission \& software \& information technology services gradually increase with jumping from the 10th in 2008 to the third, and get a rapid development between 2008 and 2012. (11) The trends of the wholesale \& retail trades \& hotels \& catering industry are basically the same as that of transportation \& storage \& postal industry, however the contribution ratios are much higher than the latter.

\section{Conclusions and Suggestions}

This paper uses the statistical analysis method to analyze the data of value-added economic growth in Henan province, by constructing a classification value-added growth loading coefficients to study the dominant driving forces and potential driving forces in the future of provincial economic growth. The results show that the major driving forces of provincial economic growth in 2012 are derived from animal husbandry, forestry, information transmission \& software \& information technology services, and construction industries, etc., as well as the potential driving forces in the future come 
from transportation \& storage \& postal industry, services of farming \& forestry \& animal husbandry \& fishery, wholesale \& retail trades \& hotels \& catering industry and farming, etc..

From 2008 to 2012, the regional economy of Henan province obtains a considerable development, the value-added of the national economy increases rapidly and the living standard of the people updates to a new level, meanwhile there are a great deal of development potentials as well, and the significant differences in industry developments.

On the strategy of Central Plains Economic Region in the state key development background, the only way to obtain a better level of the entire provincial economy and truly play the strategic role in linking the east to the west is going through the balanced development of various industries and mining the potentials of industry developments.

The specific suggestions are following: (1) It is necessary to take a full advantage of traditional agricultural province, adjust the structure of farming production, play the full leading role of the farming economy in driving provincial economic growth, meanwhile guarantee the good momentum of animal husbandry production. (2) Under the national focus on the development of "smart region" background, it is necessary to continually play a leading role of emerging industry as information transmission \& software \& information technology services, and maximize the construction of high value-added field as the hardware and software development, data processing and transmission. (3) It is necessary to take full advantages of Henan as a traditional industrial province, adjust the structure of industrial production, continually maintain and increase the scale of high value-added industrial production. (4) It is necessary to take a fully regional advantage of Henan, vigorously develop the transportation \& storage \& postal industry, increase the economic benefits of the logistics and passenger.

\section{References}

[1] Wenliang Zhao, Wenfeng Chen, Deyou Meng, Development of temporal-spatial pattern of economic development in central plain economic zone, Economic Geography. 31 (2011) 1585-1591.

[2] Yingchun Gong, Juan Feng, Jing Luo, Research on time and space characteristics of the three new-type coordinated development level of the central plain economic region, Areal research and development, 32 (2013) 158-171.

[3] Xuning Qiao, Ting Zhang, Chunhua An, et al., Accessing on corrdination degree of region development in Henan province, Areal research and development, 33 (2014) 33-38.

[4] Jie Fan, The Strategy of Major Function Oriented Zoning and the Optimization of Territorial Development Patterns, Bulletion of Chinese Academy of science, 28 (2013) 193-206.

[5] Baoqi Xue, Analysis of spatial evolution features of economy pattern in Henan province. Areal research and development, 32 (2013) 44-48.

[6] Jinmei Xia, An empirical analysis and mechanism innovation research of the residents' property income gap between urban and rural areas in Henan province, Journal of Xinyang normal university (Philos. \&Soc.sci.Edit.), 34 (2014) 54-57.

[7] Kun Liu, Yuming Shen, Wang Zhang, et al., Study on the industrial association effect in Henan province, Areal research and development, 32 (2013) 29-34.

[8] Zeng Tang, Xingyong Han, Classification and Differences of China's Aquatic Fingerlings Industry Based on Factor Analysis, Chinese Agricultural Science Bulletin, 32 ( 2014) 89-94.

[9] Jiangmin Pan, Research on the classification standards of national economy industry, Science and practice of statistics, 6(2012)16-18. 